\title{
Definition and Types of Time Management Obstacles for Nursing
}

\author{
Mohammad Qtait RN, MSN ${ }^{* 1}$, Seyyan alarab RN, MSN ${ }^{2}$ \\ Palestine Polytechnic University, Hebron, Palestine, Hebron Government Hospital, Palestine \\ Palestine Polytechnic University, Hebron, Palestine
}

\begin{abstract}
Aim: This paper critically examines the research literature relating to the obstacles time management and definition of time management. Background: Time management is a skill and behaviors that become a aspect of one's individual and professional life, it is the key to increase the productivity of nursing, but also helps to copy tension more efficiently. During the last years, there has been growing recognition of the status of time in today's global and fast growing society, and increasing in technology. Method: This review contain 27 empirical studies and book on time management conducted between 2000 and 2018, by research in google. Findings: thorough search for the existing literature revealed a lack of study related to obstacles of time management, and discuss the concept obstacles of time management in nursing work and concern the obstacles of time management techniques. This review offers an overview of research on time management and obstacles of time management. The reviewed research displays many limitations as. First, time management has been defined and operationalized in a different of ways. Some instruments were not trustworthy or valid, which could account for unstable findings. Second, very little attention was given to nursing and health field. There is a need for more accurate research into the obstacles of time management in nursing and health professional. Conclusion: Review of article for obstacles time management, time management important for nurses, and effect on performance. Little study in obstacles of time management for nurses, study appear type of time management obstacles personal, administration and organizational obstacles, method of measurement of obstacles by experiment and questionnaire
\end{abstract}

Keywords: obstacles, time management, nursing

\section{Introduction}

Time management return to a procedure constituted of a group of steps in which it involves the test of our time custom, clarification of our objectives, establishment of our priorities, planning for appropriate results, commitment, and taking positive work against time wasters. ${ }^{[8]}$

Time management is a method for managers to increase work effeciancy and effectiveness it is probably not simple as it is imagined and expected to be. Hence, authors differ in the way which they defined time management. In their study on, "time management: efficancy, logic and challenges", ${ }^{[5]}$ have noted that the term time management means different things to different people.

According to factors affecting time management (personal and administration obstacles) about nursing performance in Hebron hospitals, these factors are; time management (Analyzing time, follow-up, planning time, and time commitment), personal as (uses phone, fear from mistakes) and administrative obstacles of time management as(lack priorities or plans daily, Lack of incentives, Procrastination), and nursing performance.

Time management is important in the nursing because the time wasted by nurses, is the time not spent with the patient and it has a negative effect on the quality of care given to patient interruption as "when an external force, such as phone ringing or a person walking into your office and asking a question, breaks your attention". Nursing are the primary hospital caregivers, and the efficient use of their time and energy is critical to the future of American hospitals, the study evaluated the time that nurses spent and the distance that they traveled across 36 geographically diverse medical-surgical units, the results demonstrate that nurses devote large proportions of their time to documentation, medication administration, care coordination and somewhat less time to patient care activities, nurses also travel significantly larger distances and exert more energy during daytime shifts than when out of work.

Knowledge of the causes and factors of obstacles time for nurses, and finding an appropriate administrative environment to avoid and to reduce these factors can effectively raise and improve the productivity of nursing and hospitals staff as a whole.

Nurses spent around $37 \%$ of their time with patients, work patterns were increasing with rapid changes between tasks at short time. Interruptions were modest but their substantial over-representation among medication tasks raises potential safety concerns. There was no evidence of an increase in team-based, multi-disciplinary care.

Over time, nurses spent significantly less time talking with colleagues and more time alone, the definition of obstacles time First, telephone, paperwork, stop copying machine, and the modern social show clearly as wasting of their time, but if they make a serious effort to clarify the definition, some of the difficulties Show clearly, for those who considered this time-consuming activity for you or the other person. 


\section{International Journal of Innovative Research in Medical Science (IJIRMS) Volume 03 Issue 10 Oct 2018, ISSN: 2455-8737, Imp. Factor - 4.102 \\ Available online at $-\underline{w w w . i j i r m s . i n}$}

\section{Objectives of the study}

The quality of health care delivered to patients and the outcomes of the overall hospital services as a result of the work overload pressure among the hospital staff is an important indicator to assess their time management obstacles. Nurses' work overload all the time will not allow them to have sufficient time to provide quality care where very high working efficiency is needed to achieve the minimum health care requirements in hospitals.

Health care systems changing rapidly causing fundamental transformations that has an impact on employee well-being and organizational goals. (Many health care workers are not copying with their personal and work-related demands, these problems are seriously impacting on patient care and employee productivity, recognizing the importance of time management among nurses and its impact on their performance which should be reflected on their satisfaction and thus on the productivity of health institutions they are working with.

The human element is the most important thing we have, and the most important productive and distinctive resource to have a distinct competitiveness if the hospitals' management knew how to exploit these human elements.

Time management has become more important for all as they seek to accomplish objectives in today's organizations which have been restructured for efficiency while employing fewer people, managers can improve their ability to manage time effectively by examining their attitudes toward time, analyzing time-wasting behaviors, and developing better time management skills, they can improve their performance and promotion potential with more effective time utilization. Strategies for improving time management skills are presented as knowledge of the causes and factors of obstacles time for nurses, and finding an appropriate administrative environment to avoid and reduce these factors effectively on the other hand improve the productivity of nurses and hospitals staff as a whole.

\section{Method}

Empirical studies on time management published between 2000(when time management was introduced) and 2018 were found through google. Query terms included time management, time definition, in nursing and health professional. A first criterion for the selection of studies was that time management for nurses. The second criterion was that time management and time obstacles

Using these two criteria, 27 empirical studies and book for time management in nurses were selected for inclusion in this review. We will discuss these studies by presenting the theoretical contributions made, the definition of time management used, and time obstacles and suggestions for future research.

\section{Indicators of time management}

As for many people see time management as a rather narrow or single issue, however, time management is multidimensional,thus reaches into every aspect of our daily lives, no matter how hectic or tight is our daily schedule still time has to be managed effectively. According to time mastery system it includes fourth steps, which are;
1. Analyzing time use: Discover what is happening and what should be changed.

2. Follow-up of time

3. Planning time: Make sure that activities land to the stated objectives.

4. Time commitment.

The results of the present study showed that among the studied variables influencing time management, goal setting was the highest priority and affecting variable otherwise meetings management was the lowest priority and the most affected one. As goal setting is the first step in effective time management and represents the quality and method of spending time by employees in the future, more investment in this variable and setting precise and measurable objectives by the managers can save time in later stages. In order to achieve correct and proper time management, it is recommended setting and prioritizing clear goals and objectives, as well as determining and clarifying tasks accurately. In this regard, increasing hospital managers' knowledge about time management and the need for accurate goal setting through providing time management courses, and requiring them to develop a time management plan can improve their abilities to manage the time.

According to this study which investigates how Iranian nursing students manage their time according to the circumstances and obstacles of their academic field, Twenty-one nursing students were purposefully chosen as participants, data was collected through semi-structured interviews and analyzed using the method suggested by Corbin and Strauss, one of the three processes that the nursing students used was "unidirectional time management." This pattern consists of accepting the nursing field, overcoming uncertainty, assessing conditions, feeling stress, and trying to reduce stress and create satisfaction, it was found that students allotted most of their time to academic tasks in an attempt to overcome their stress.

\section{Benefit of control time management obstacles}

Time Management is the away which used to organize our time, so each decision

We make regarding that is useful, constructive and the most beneficial to our life's

structures also time management in nursing also is important feel less stressed, when nurses know what they need to do and have a plan for doing it along with the necessary room in their schedule to deal with unexpected crises, they will feel more positive about their extremely important jobs,obstacles of the time management in the organization can lead to poor management which lead to time loss for employees, and poor performance.

According to the importance of time management and its vital role in the quality of nursing care for clients, and also the fact that head nurses believed more in their time management behaviors, they are expected to improve organization's goals and developments in order to modify the weaknesses and shortages and promote the skills and capabilities of their staffs and also resolve the disagreement on the understanding of time management. Moreover, effective time management training programs can be an important step for staff nurses and their head nurses 


\section{International Journal of Innovative Research in Medical Science (IJIRMS) Volume 03 Issue 10 Oct 2018, ISSN: 2455-8737, Imp. Factor - 4.102 \\ Available online at $-\underline{w w w . i j i r m s . i n}$}

\section{Obstacles and Types of Time Management}

Defined obstacles of time as "all that prevents you from achieving your goals effectively" such as telephone use, paperwork, poor planning and poor communication. The classification types of time management obstacles as; Personal as lack of planning and priorities, and Management and organization obstacles as organization, employment, direction, control, communication, and decision making. The main time management waster include interruptions, distractions, procrastination and dealing with lateness. Let's analyses each of these challenges in detail.

TM (time management) techniques promote job performance, provide more time to carry out the tasks with higher priority and accelerate the activities. ${ }^{[23]}$

The administrative process is a synthesis of sequential operations (Planning, organizing, directing and censorship); wasting of time at the planning stage may be putting no aims or even not determining deadline to finish tasks, and the time wasting at the organizing stage may be caused by presence of multiple tasks and giving no

priorities to any of them and that may lead to duty disclaimer, wasters at the directing stage are represented in caring for unimportant details and weakness in establishing group rapport between workers, and finally the wasting of time that relate to censorship are represented in plenty of visitors to workers and ignoring the mistakes done by workers most of the time.

Conducted a study which aimed at finding the Obstacles of time management and decision-making to the education departments of government schools in the West Bank, Palestine through detecting the obstacles of time management and decision-making to the education departments of government secondary schools and developing of suitable suggestions to reduce them.

\section{Personal Obstacles}

agreed that obstacles of the time management is a result of the organization poor management, leading to time loss for many of its employees, they further reiterated on the causes of obstacles could be due to increase the number of meetings and communication systems, unplanned visits and meetings, fear to take decisions and fear of making mistakes.

One of the factors that lead to constraint for doing the job on time during working hours as been noted by the study investigator is employees' irresponsibility, the employees' follow-up matters and personal transactions, use the telephone and the Internet for personal matters without control and talk with colleagues about matters that does not belong to the work. In addition, many are disorganized and spend too much time looking for lost items prior to performing any procedure related to his work.

The lack of planning and priorities; many people never get anything accomplished because they don't know where to begin or how to proceed once started, it is important that you keep schedule by Listing your priorities in order of importance, If needed, discuss the priorities with your boss or coworkers. Make a schedule that starts at the beginning and incorporates all of your priorities into the schedule with goals for completion dates, list every hour and what you should be working on for that hour.
The number of employee inflation; increasing the number of employees that cause time obstacles, because the people like to meet with each other and make visits and conversations, the manager spends more than $(10 \%)$ of his time in solving problems and conflicts as a result of human relations between the employees, initiation of a task without thinking and planning, moving to a new task before completion of previous task and attention to matters of low importance are factors that may increase the tension which block the work if it happen. And added to the mentioned above, time constraints can also arise due to weak means of communication between management and the various departments.

The behavior by the individual worker itself, lead to nonexploitation of the time allocated for the optimal exploitation of the work, where each of the indicated personal obstacles that lead to go time which can be identified in:

1. Reading newspapers, magazines and periodicals in the work hours and within the organizations during the working hours Official.

2. Family insurance needs of the family in an exaggerated manner.

3. Follow-up matters and personal transactions.

4. Delivery of children from home to school and vice versa, while it can be done by the others.

5. Use the telephone and the Internet in personal matters without controls.

6. Receiving visitors are unplanned.

7. Delay the start time.

8. Leave work early.

9. The large number of holidays to just consumption.

10. Talk with colleagues in other things does not belong to the work.

According to most of distractions in the modern working environment are directly related to the internet, in justification of this point, the author mentions social media sites such as Facebook, YouTube, Twitter and specifies these sites to be biggest distractions in the modern workplace.

Agrees with the above point and formulates recommendations of blocking access to entertainment websites from computers in the workplace,the author provides further recommendations to employees in management positions in terms of applying the same practice in relation to the computers of their subordinates in order to increase the overall level of organizational efficiency.

According to study about Assessment of time management attitudes among health manager was conducted at the State Hospital, Social Security Hospital, and University Hospital at Kirikkale, Turkey between October 1999 and January 2000, including 143 subjects defined as medical managers and medical specialists. According to the results, a manager should give priority to the concept of planning, which may be counted among the efficient time management techniques, and educate him/herself on time management.

\section{Management and organizational obstacles}

The obstacles that prevent the optimal use of time were indicated in more details as time obstacles to permeate the various administrative processes as follows: Planning, organization, 


\section{International Journal of Innovative Research in Medical Science (IJIRMS) Volume 03 Issue 10 Oct 2018, ISSN: 2455-8737, Imp. Factor - 4.102 \\ Available online at - $w w w . i j i r m s . i n$}

employment, direction, control, communication, and decisionmaking.

The obstacles that prevent the optimal use of time, where indicated to briefly while listed are more detailed, and time obstacles to permeate the various administrative processes, as follows: -

\section{Control of time obstacles}

The study examines the effective time management practice and its effect on nursing performance, the findings of time management was high on Hebron hospitals, and personal obstacles low, the administration obstacles were high on Hebron hospitals.

Hebron hospitals interest for time management (time analysis, time committed, time planning, Follow-up of time).

The foundation was recorded that time using is a good method to identify areas of obstacles of time in your life and enabling to reduce these through recording every job doing days in details and then reviewed to identify how you use your time".

The effectiveness of time management is the key to improving the quality of life, neither time nor lost opportunities can be restored, but we can take advantage of current and future time, it can be achieved by skilled self-management in a timely manner, or in other words, create the possibility of fulfilling one's responsibilities better and faster, time management effectively, depends on two factors: planning work and focusing on details.

\section{Instruments used for measuring obstacles time Management}

The last studies some used observation and experiments, generally different types of self-reported questionnaires were used to measure time management obstacles, three types of which were used more often, measure by questionnaires and divided personal and organizational obstacles and use different items

\section{Findings}

Thorough search for the existing literature revealed a lack of study related to obstacles of time management, and discuss the concept obstacles of time management in nursing work and concern the obstacles of time management techniques. This review offers an overview of research on time management and obstacles of time management. The reviewed research displays several limitations. First, time management has been defined and operationalized in a variety of ways. Some instruments were not reliable or valid, which could account for unstable findings.. Second, very little attention was given to nursing and health field. There is a need for more rigorous research into the obstacles of time management in nursing and health professional.

\section{Future research}

Recommended on time and its importance for nurses and how to manage and exploit to the fullest and how to avoid obstacles of time.

\section{Conclusion}

Review of article for obstacles time management, time management important for nurses, and affect on performance. study on obstacles of time management for nurses, study appear type of time management obstacles personal, administration and organizational obstacles, method of measurement of obstacles by experiments and questionnaire.

\section{Declaration of interest}

The authors report no conflicts of interest, the authors alone are responsible for the content and writing of this article.

\section{Reference}

[1] Abu Sakour,Tyseer Abdalhameed (2003). Obstacles to time management and Decision-Making to the Education Departments of government Secondary Schools in the West Bank, Palestine. A doctoral dissertation. ain shams university,Egypt.

[2] Alwan, Qasem Nayf \& Ehmeed, Najwa Ramadan (2009). Time Management, Applications of the Concepts of operations, the House of Culture for Publishing and Distribution, Amman, Jordan.

[3] Al-Zahraina,(2006). time management for guarded in Macca, thesis master, university of nyafe, Rayed Suadia Arabia.

[4] Bahadori M, Salesi M, Ravangard R, Hosseini SM, Raadabadi M, Hojati Dana A, et al.(2015) Prioritization of factors affecting time management among

[5] Claessens, Stijn, M. Ayhan Kose, and Marco E. Terrones, 2009, "What Happens During Recessions, Crunches, and Busts?” Economic Policy, October, pp. 653-700

[6] Evans, C. (2008) "Time Management for Dummies" John Wiley \& Sons Fleming, I. (2011) "The Time Management Pocketbook" 6th edition, Management Pocketbooks

[7] Gupta, C.B. 2001. Management Theory and Practice. 6thEdition. Sultan Chand and Sons, New Delhi. Hall at the University Press, Cambridge UK.

[8] Hashemzadeh GR, Ranjbar V, Moosavi ST, \& Eidi $\mathrm{F}(2011)$. The Role of Organizational Culture in the Establishment of Time Management (A Case Study: Mines and Mineral Industries).Aust. J. Basic \& Appl. Sci 2011

[9] Hassanzabeh R, Ebadi AG (2007). Measure the share of the effective factors and time management, World Applied Science Journal 2(3):168-174.

[10] Hendrich, A., Chow, M. P., Skierczynski, B. A., \& Lu, Z. (2008). A 36-Hospital Time and Motion Study: How Do Medical-Surgical Nurses Spend Their Time? The Permanente Journal, 12(3), 25-34.

[11] Melhim, Mohammad,(2010) An Analytical Study concerning the relationship between Time Management and Employees' Performance with the application of public and private institutions at Qalqilia Governorate Palestine,(2010).

[12] Nasri Sh, Pazargadi M, Zagheri Tafreshi M, Nassiri N. The Correlation of Head Nurses' Time Management with Nurses' Job Satisfaction in Medical \& Surgical Wards of Hospitals in Arak Medical Sciences University. Journal of Nursing and Midwifery. 2013;22(79):1-7. [Ref list]

[13] Qtait, M. T. (2017). Time management for nurses, Publisher LAP Lambert Academic Publishing, 2017 ISBN $\quad 3330345888,9783330345881$ 
[14] Qtait,M. (2016), The Actual Time Management of Nurses in Hebron Hospital, Public Policy and Administration Research, ISSN 2224-5731(Paper) ISSN 2225-0972(Online) Vol.6, No.7,

[15] Qteat,M. and Sayej, S. (2014): Factors Affecting Time Management and Nurses' Performance in Hebron Hospitals. Journal of Education and Practice. 5(35):4185.

[16] Richard Whipp, Barbara Adam, Ida Sabelis, 2002Making Time Oxford University Press Inc, New York, United States

[17] Roe, R. A. (2000). Work performance: A multiple regulation perspective. In C. L. Cooper \& Robertson I. T. (Eds.), International review of industrial and organizational psychology, volume 14 (pp. 231-318).

[18] Silvis, C. (2011) "Time Management and Organisation for Writers" in 2012 Writer's Market

[19] Sufyni, Abd A 1 mode, (2001). time management and application, master thesis am al quark university KSA

[20] Woodcock, B.How to manage your time effectively. Page maintained by (available at 15-10-2014).
[21] Wrona K., el, 2012. EFFECTIVE TIME MANAGEMENT SELECTED ISSUES, marketing of scientific and research organizations.

[22] MOH Health Report, 2011).

[23] Belal Said N. Time Management in Nursing Work. International Journal of Caring Sciences. 2014;7(3):746749.

[24] Edwin Arnold, Marcia Pulich, Improving Productivity Through More Effective Time Management The Health Care Manager Volume 23, Number 1, pp. 65-70 \# 2004, Lippincott Williams \& Wilkins, Inc

[25] Ebrahimi, H., Hosseinzadeh, R., Tefreshi, M. Z., \& Hosseinzadeh, S. (2014). Time management behaviors of head nurses and staff nurses employed in Tehran Social Security Hospitals, Iran in 2011. Iranian Journal of Nursing and Midwifery Research, 19(2), 193-198.

[26] Sarp N, Oren DA, Winser KL, Spinelli M. (2005). Assessment of time management attitudes among health manager. Health Care Manag.; 24:228-32.

[27] Mirzaei, T., Oskouie, F., \& Rafii, F. (2012). Nursing students' time management, reducing stress and gaining satisfaction: a grounded theory studynhs. 